\title{
A IMPORTÂNCIA DA INTERVENÇÃO EDUCATIVA AOS ENFERMEIROS DA ATENÇÃO BÁSICA PARA A PREVENÇÃO DO HELICOBACTER PYLORI
}

The importance of educational intervention to primary care nurses for helicobacter pylori prevention

Daniela Machado, Morgana Vanessa Barreto, Karina Cardoso Gulbis Zimmermann, Valdemira Santina Dagostin, Maria Salete Salvaro, Maria Teresa Soratto

Curso de Enfermagem - Universidade do Extremo Sul Catarinense - UNESC Criciúma - SC - Brasil

\section{Endereço para correspondência:}

Karina Cardoso Gulbis Zimmermann

Curso de Enfermagem

Universidade do Extremo Sul Catarinense - UNESC

Avenida Universitária, 1105

Criciúma - SC

CEP - 88806-000

Email: karina@unesc.net 


\section{Resumo}

Tratou-se de um estudo qualitativo realizado por pesquisa aplicada, descritiva, exploratória e de campo com o objetivo de aplicar uma intervenção educativa aos enfermeiros da atenção básica para a prevenção da infecção por Helicobacter Pylori (HP) na atenção básica. Participaram do estudo 15 Enfermeiros atuantes em 15 Unidades Básicas de Saúde (UBS) de um município do Extremo Sul Catarinense. Os dados foram analisados por meio da técnica de categorização e análise de conteúdo proposta por Minayo, onde foram levantadas as seguintes categorias norteadoras da entrevista: Compreensão sobre HP: primeiro passo; conceitos básicos, riscos e desafios para a saúde coletiva; a transmissão: mecanismos e necessidade de ações para a prevenção; riscos eminentes à saúde; diagnósticos; tratamento medicamentoso e educação em saúde; modelo biomédico de atenção; e por fim relato da prática da intervenção educativa. Percebe-se que o conhecimento do processo fisiopatológico da HP precisa ser lapidado, uma vez que é um assunto pouco debatido desde o ensino universitário ou após ele. Além disso, os enfermeiros entrevistados no presente estudo demonstraram que em sua prática cotidiana não se apropriaram dessa temática e, portanto, o foco principal dessa temática é o tratamento quando se têm alguém acometido com a bactéria. Todavia, a atenção se volta apenas para a competência médica, uma vez que o tratamento descrito é o medicamentoso. Desse modo, percebe-se um distanciamento do enfermeiro tanto na prevenção a partir da educação em saúde, quanto durante o tratamento, demonstrando a dificuldade para a promoção da saúde e a prevenção de doenças. Sugere-se que o enfermeiro trabalhe a temática nos grupos das UBS e em orientação individual, e não somente ofereça sua atenção diante de um diagnóstico positivo, mas também visando à prevenção da infecção. Para que isto de fato ocorra é importante que a educação permanente em saúde ocorra por intermédio da secretaria municipal de saúde, bem como dentro das equipes, para subsidiar a atuação no município.

Palavras-chave: Helicobacter Pylori; Educação em Saúde; Educação Continuada; Educação Permanente; Atenção Primária a Saúde. 


\section{Abstract}

This was a qualitative study by applied descriptive, exploratory and field research in order to implement an educational intervention to nurses of primary care for the prevention of Helicobacter Pylori (HP) infection in primary care. Study participants were 15 nurses of Primary Care acting in 15 Basic Health Units of a municipality in the extreme south of Santa Catarina. The data were analyzed using content analysis and categorization technique proposed by Minayo, where the following guiding categories of the interview were raised: Understanding about HP: first step; basics risks and challenges for collective health; transmission: mechanisms and need for actions to prevent; eminent health risks; diagnostics; drug treatment versus health education; biomedical model of attention and finally reporting the practice of educational intervention. It is noticed that the knowledge of the pathophysiological process of HP need to be improved, since it is a subject rarely discussed since the university education or after it. In addition, the nurses interviewed in this study showed that in their daily practice they have not embraced this issue and therefore the main focus of this theme is the treatment when there is someone affected with the bacteria. However, attention turns to the medical expertise, since the therapy described is the drug therapy. Thus, we can see a nurse detachment in the prevention from health education as well as during treatment, demonstrating the difficulty for health promotion and disease prevention. It is suggested that nurses work the theme in the thematic groups of UBS, and individual guidance and not only offer their attention in front of a positive diagnosis, but also for the prevention of infection. For this occurs is important that the permanent health education occurs through the municipal health department and, within teams to support the activities in the city.

Keywords: Helicobacter Pylori; Health Education; Continuing Education; Constant Education; Primary Health Care. 
O Helicobacter Pylori (HP) é uma bactéria Gram negativa identificada pela primeira vez na mucosa gástrica em meados dos anos 80 por Marshall e Warren. Nesta época acreditava-se que nenhuma bactéria poderia sobreviver em meio ácido como o do estômago, de modo que a descoberta causou incredulidade no meio científico ${ }^{1}$.

Sabe-se que o principal modo de transmissão deste microorganismo geralmente se dá via oral-oral e fecal-oral, porém ainda não é possível determinar por qual via a transmissão predomina. "É provável que ambas atuem simultaneamente em níveis populacionais"2.

Há evidências que também possa ocorrer transmissão iatrogênica da HP por meio de aparelhos endoscópicos ${ }^{2-4}$.

Os países subdesenvolvidos apresentam maior prevalência de infecção por HP do que os países desenvolvidos, uma vez que a água contaminada por matéria fecal, moradias com aglomerações familiares e condições precárias de saneamento básico são considerados fatores de risco para infecção pela HP. A maioria dos estudos afirma que o fator socioeconômico na infância configura-se como principal fator de risco, porém a HP pode ser adquirida em qualquer faixa - etária ${ }^{3-5}$.

Rodrigues et al., em estudo realizado com 200 crianças de 2 a 13 anos em município de Rondônia, mostrou a prevalência de soropositividade para HP em 51\% das crianças de baixo nível econômico, enquanto $24 \%$ das crianças de classe média eram positivas.

Percebe-se que a HP é uma bactéria de distribuição cosmopolita e que cerca de $50 \%$ da população mundial está infectada ${ }^{7}$. No Brasil estima-se que mais de $70 \%$ da população pode estar contaminada pela bactéria ${ }^{8}$, o que requer atenção redobrada no que tange à prevenção e/ou acompanhamento efetivo no tratamento para que de fato isso ocorra.

A infecção pela HP induz à inflamação persistente na mucosa gástrica, que determina gastrite crônica não-atrófica, progredindo para gastrite atrófica, metaplasia intestinal, displasia e carcinoma gástrico. Entretanto, o desenvolvimento e a distribuição destas lesões dependem de fatores de virulência da bactéria e resposta imune do hospedeiro 9 . 
O estilo de vida também influencia no surgimento de lesões gástricas em pacientes HP positivos, e o consumo de irritantes da mucosa gastrointestinal, como tabaco, álcool, café e condimentos, podem aumentar o risco do desenvolvimento de úlcera péptica ${ }^{5}$.

A HP desempenha forte relação à fisiopatologia da doença ulcerosa péptica, estando presente em mais de $90 \%$ de pacientes com úlceras gástricas ou duodenais. Destaca-se que a úlcera péptica é considerada lesão precursora do câncer gástrico, que atualmente é a segunda causa mais comum de morte por câncer no mundo e é a $3^{\underline{a}}$ neoplasia com maior incidência no Brasil ${ }^{5}$.

A prevalência da infecção pela HP é considerada um problema de saúde pública ${ }^{2}$. Diante desta realidade acredita-se que somente com o desenvolvimento de estratégias com enfoque na prevenção é que as taxas de contaminação pela HP poderão ser reduzidas, mas para isso é essencial ter conhecimento sobre os fatores de risco e mecanismos patogênicos desta bactéria ${ }^{2,3}$.

Apesar da forma de transmissão ainda não estar de fato esclarecida, e como ainda não há disponível uma vacina como forma de prevenção contra a infecção pela HP, considera-se prudente realizar recomendações no sentido de conscientizar sobre métodos de higiene adequados, como lavagem correta dos alimentos, higienização adequada das mãos e consumo de água potável ${ }^{10}$.

A Enfermagem é considerada uma profissão eclética em que a partir de constante busca de conhecimento e, portanto, de seu aprendizado, atua em diversos âmbitos e desenvolve as práticas de cuidado a partir de assistência ou de educação em saúde.

Rocha e Almeida ${ }^{11}$ a definem como:

[...] uma das profissões da área da saúde cuja essência e especificidade é o cuidado ao ser humano, individualmente, na família ou na comunidade, desenvolvendo atividades de promoção, prevenção de doenças, recuperação e reabilitação da saúde, atuando em equipes. A enfermagem se responsabiliza, através do cuidado, pelo conforto, acolhimento e bem estar dos pacientes, seja prestando o cuidado, seja coordenando outros setores para a prestação da assistência e promovendo a autonomia dos pacientes através da educação em saúde. 
A Atenção Primária em Saúde é considerada o primeiro contato da população com o sistema de saúde, tornando-se um ambiente favorável para o profissional da Enfermagem desenvolver estratégias de promoção à saúde, prevenção e reabilitação de doenças. Nesta perspectiva a educação em saúde é considerada como um importante meio para o desenvolvimento de ações de promoção a saúde, pois fortalece o vínculo enfermeiro- cliente, contribuindo no despertar da conscientização do cliente para a cidadania, como agente responsável pelo seu processo saúde-doença e multiplicador de conhecimento ${ }^{12}$.

De acordo com Perry e Potter ${ }^{13}$ a atenção Básica é o cenário ideal para as práticas de educação em saúde, cujas ações objetivam a melhoria do estilo de vida das pessoas através de mudanças de hábitos voltados para a higiene pessoal, boa nutrição, entre outras atitudes necessárias para a melhora da qualidade da saúde.

Contudo, a educação em saúde é um instrumento que possibilita ao enfermeiro um estabelecimento de uma relação com o cliente, no intuito de torná-lo capaz de refletir e perceber-se como um sujeito de transformação sobre sua situação de saúde-doença ${ }^{14}$.

Também é vista como um dos principais instrumentos no processo de cuidar, sendo o Enfermeiro da atenção básica o principal agente deste processo, por ser ele que desenvolve as práticas de educação em saúde em grupos. Esta é vista "como uma estratégia promissora no enfrentamento dos múltiplos problemas de saúde que afetam as populações e seus contextos sociais"14.

Mas, para tanto, se faz necessário que o Enfermeiro esteja capacitado para desenvolver suas competências, e "a capacitação representa para o profissional o domínio de conhecimentos específicos que resultam de formação, treinamento, experiência para que possam exercer determinada função"15.

Para Paschoal et al. ${ }^{16}$, tanto a educação permanente quanto a educação continuada fazem parte do processo de aprendizado e transformam a prática. Todavia, é necessário diferenciá-las. Assim, a educação continuada é vista como um mecanismo de atualização com conteúdos que favoreçam a prática, mas não aborda o ciclo do saber e fazer, do ir e vir, para aperfeiçoamento focado no cenário de trabalho do profissional, no qual percebe-se a inseparabilidade do conhecimento e da ação e no autoaprimoramento de acordo com a teoria aplicada na prática e a percepção da necessidade de maior conhecimento. 
Diante dessas reflexões tem-se como problema de pesquisa: Qual a importância da intervenção educativa aos enfermeiros da atenção básica para a prevenção da HP?

A partir do problema de pesquisa elencou-se como pressupostos: A intervenção educativa é importante para proporcionar o aprendizado dos enfermeiros; os enfermeiros sentem necessidade de aprendizado sobre a temática para efetuar a educação em saúde.

Com o intuito de proporcionar aos Enfermeiros discussões e orientações sobre a contaminação por HP para a utilização desse entendimento na prática cotidiana e de prevenção na Atenção Básica, tem-se como objetivo geral: Aplicar uma intervenção educativa aos enfermeiros da atenção básica para a prevenção da HP.

Elencaram-se, a partir do objetivo geral, os objetivos específicos: Identificar o perfil dos Enfermeiros pesquisados; reconhecer o entendimento sobre a temática HP; verificar qual a capacitação dos profissionais relacionados a HP; Identificar as orientações que os Enfermeiros realizam sobre a HP.

\section{MÉTODOS}

Trata-se de uma pesquisa aplicada com abordagem qualitativa e descritivaexploratória, uma vez que o foco deste estudo foi aplicar uma intervenção educativa com os enfermeiros para a prevenção da HP na atenção básica a partir do reconhecimento de perfil, conhecimento, capacitação e métodos preventivos utilizados pelos mesmos.

A pesquisa com enfoque qualitativo tem como objetivo desvelar os fenômenos do meio social, sem a preocupação de quantificar, mas sim interpretar e compreender por meio das percepções e dos significados produzidos pelas experiências dos participantes ${ }^{17}$.

Os estudos de alcance descritivo "buscam especificar propriedades, características e traços importantes de qualquer fenômeno que analisarmos. Descreve tendências de um grupo ou população"18. 
No que tange os estudos de alcance exploratório Hernández Sampieri et al. ${ }^{18}$ definem que:

Os estudos exploratórios servem para nos tornar familiarizados com fenômenos relativamente desconhecidos, obter informações sobre a possibilidade de realizar uma pesquisa mais completa relacionada com um contexto particular, pesquisar novos problemas, identificar conceitos ou variáveis promissoras, estabelecer prioridades para pesquisas futuras ou sugerir afirmações ou postulados.

Para a efetivação do estudo tiveram-se como participantes 15 enfermeiros atuantes na Atenção Básica de Saúde de um município do Extremo Sul de Santa Catarina. Essa amostra foi intencional, uma vez que se buscou por indivíduos com características peculiares ${ }^{19}$, como ser enfermeiro e trabalhar na Estratégia de Saúde da Família.

Em respeito aos pesquisados, a pesquisa apenas iniciou após aprovação do comitê de ética em pesquisa sob o parecer $n^{\circ} 770.9953 / 2014$. Além disso, foram respeitados os quesitos contidos nos aspectos éticos da Resolução 466/12 do Conselho Nacional de Saúde, que versa sobre Diretrizes e Normas Regulamentadoras sobre Pesquisa envolvendo Seres Humanos, que deverão tratálo com dignidade, respeito e defendê-lo em sua vulnerabilidade, caso essa exista.

De acordo com a Resolução 466/1220, que trata das diretrizes e normas regulamentadoras de pesquisas envolvendo seres humanos, os participantes devem ser esclarecidos sobre a "natureza da pesquisa, seus objetivos, métodos, benefícios previstos, potenciais riscos e o incômodo que esta possa lhes acarretar, na medida de sua compreensão e respeitados em suas singularidades". Além disso, incorpora referenciais da bioética: "autonomia, não maleficência, beneficência, justiça e equidade"20.

Os dados foram coletados em dois cenários e em etapas distintas. Primeiramente houve a apresentação da proposta, solicitação de participação na pesquisa mediante a assinatura do Termo de Consentimento Livre e Esclarecido (TCLE) para posterior agendamento da visita. Após, com uma data pré-estabelecida, foi realizada a visita e entrevista semiestruturada para coletar os dados. Em uma segunda etapa foi realizada a intervenção educativa em um dia de reunião dos profissionais em que as pesquisadoras abordaram o tema, orientando para a atuação prática, realizando ao final uma breve avaliação dessa atividade. 


\section{RESULTADOS E DISCUSSÃO}

A interpretação dos dados qualitativos foi realizada pela análise de conteúdo com categorização dos dados, através da ordenação, classificação e análise final dos dados pesquisados e relato de experiência da intervenção prática.

A análise e interpretação dos dados é o "momento em que o pesquisador procura finalizar o seu trabalho, ancorando-se em todo o material coletado e articulando esse material aos propósitos da pesquisa e à sua fundamentação teórica"21.

A partir das falas dos participantes foram estabelecidas categorias de análise que foram melhor explicadas e analisadas.

\section{Caracterização do perfil da equipe de enfermagem}

O perfil dos entrevistados aborda itens importantes para compreender quem são esses profissionais. Os profissionais enfermeiros são todas do gênero feminino e apresentam idade entre 27 e 52 anos, apresentando diferenças em relação a momentos de construção de conhecimento e realidades muito diferentes na graduação. Embora se acredite que a diferença de idade não necessariamente pode estar relacionada à competência e ao tempo de formação das pessoas.

De acordo com Pastore e Rosa 22 "o setor da saúde tem se caracterizado pela forte existência da divisão sexual do trabalho onde predominantemente as mulheres atuam nas funções voltadas essencialmente ao cuidar".

Outro item analisado foi à especialização profissional destas enfermeiras que trabalham na atenção básica, as quais estão direcionadas para a saúde coletiva, pois teve-se especialização em Saúde Pública, Saúde da Família e Gerenciamento de Unidades do SUS.

Quanto ao tempo de atuação do Enfermeiro na atenção Básica, observa-se que é variável, pois há profissionais recentes com quatro meses até os que se encontram há 14 anos nesse cenário, o que leva a pensar na consolidação prática desses profissionais com mais tempo de serviço. 
Em relação à capacitação referente à HP nota-se ausência de atualização formal sobre o tema abordado.

"Atualizar os enfermeiros sobre a HP para podermos passar para os grupos e comunidade" (E1).

"É um tema bem interessante, pois está sendo comum $O$ diagnóstico positivo de HP. A intervenção seria interessante" (E2).

"Eu sugiro uma capacitação para os enfermeiros" (E6).

"Que a gente tenha uma capacitação para poder trabalhar com educação continuada, aproveitando os grupos que já existem na UBS. Existem assuntos que passam despercebidos pelo enfermeiro da UBS, por conta da demanda" (E7).

Segundo Ceccim e Feuerwerker (2004, p. 43):

A formação para a área da saúde deveria ter como objetivos a transformação das práticas profissionais e da própria organização do trabalho, e estruturar-se a partir da problematização do processo de trabalho e sua capacidade de dar acolhimento e cuidado [...].

Categoria 1 - Compreensão sobre a HP: primeiro passo

A criticidade acerca da comunidade, em seu meio de vida, respeitando as diferentes situações, bem como o sujeito como participativo no processo voltado à reflexão crítica da realidade e de fatores que denotem um viver saudável imerge nesse campo da construção do conhecimento e na prática da educação em saúde ${ }^{23}$.

Nesse contexto, atenta-se para o fato de que conhecimento provém de aprendizado prévio, para tanto, requer do profissional o aprofundamento. 
Artigo Original

Atenção à Saúde

Subcategoria 1: Conceitos Básicos, riscos e desafios para a saúde coletiva

Os enfermeiros pesquisados aproximam seus entendimentos aos descritos na literatura, mas isso não ocorre de forma a demonstrar um entendimento no que tange o conceito.

"É uma bactéria que tem no estômago (E1, E2, E7, E8, E11, E12, E13 e E15), causa dor e precisa de reeducação alimentar e tratamento" (E2).

"É uma bactéria que pode ser contraída através da alimentação, o meio que ela vive é o estômago. Sei pouco sobre o assunto" (E4).

"É uma bactéria do estômago, descoberta através de endoscopia. Geralmente desenvolvida em paciente com gastrite. O Paciente com HP passa pelo Médico e ele quem orienta e prescreve o tratamento" (E6).

"Nenhum conhecimento. Sei que é uma bactéria que se instala no estômago" (E9).

"Acho que é bactéria. Não me lembro deste assunto ter sido abordado em algum momento, nem durante a graduação e enquanto enfermeira" (E14).

O processo fisiopatológico, inclusive com citação dos danos acarretados, foi mencionado, como a dor (E2, E5), possibilidade de úlcera (E3) ou gastrite (E6). O que denota uma série de sinais e sintomas que podem ser analisados para evitar complicações mais severas.

Percebendo pela fala de E1, verifica-se que todo o trajeto gastrointestinal foi mencionado como estômago e intestino. E9 e E15 também acreditam que o intestino possa ser colonizado por esta bactéria, mas não têm certeza. A enfermeira E6 


\section{Artigo Original}

\section{Atenção à Saúde}

expressa dúvida de que talvez a bactéria pudesse colonizar outros órgãos além do estômago e intestino, mas não aprofunda. Todavia, em todos os estudos pesquisados não se observou relatos de que a HP possa colonizar outros órgãos do organismo se não a mucosa gástrica e duodenal, e, conforme Barbosa e Schinonni ${ }^{24}$, a última porção acometida é o duodeno, e não todo o intestino.

Além disso, verifica-se que há falas que relatam que sabem pouco do assunto (E4, E14), ou que o assunto é mais do médico (E6). Contudo, observa-se um predomínio do modelo biomédico de atenção ao invés de um modelo assistencial interdisciplinar voltado à promoção da saúde. Ficou evidente quando a enfermeira enfatiza que a responsabilidade do cuidado de um paciente HP positivo é do médico (E5, E10), mostrando uma forma de cuidado centrado apenas na cura e despreocupado em promover estratégias de promoção à saúde sobre a temática.

Nota-se que o déficit de conhecimento por parte da enfermagem sobre 0 assunto, como evidenciado na fala de E14, que em nenhum momento recebeu capacitação sobre o tema nem mesmo na vida acadêmica, corrobora a prática de uma assistência onde o médico é principal profissional responsável pelo cuidado.

Percebe-se a partir deste contexto a necessidade de se trabalhar com educação permanente em saúde na busca de um modelo de assistência de saúde preocupado em prestar uma assistência voltada à integralidade do cuidado e o empoderamento do enfermeiro como profissional primordial no processo de educação em saúde na comunidade onde atua.

Subcategoria 2: A transmissão: mecanismos e necessidade de ações para a prevenção

Os enfermeiros entrevistados atribuíram às práticas alimentares o principal meio de contaminação pela bactéria. Consideram que a transmissão se dá pela higienização inadequada dos alimentos (E1, E3, E4, E5, E6, E10 e E15). Além disso, atribuem o contágio da bactéria a maus hábitos alimentares, como ingestão de alimentos gordurosos ou com teor ácido, assim como à demora entre as refeições (E2, E12, E13). Também consideram a ingestão de água não tratada como meio transmissão da bactéria (E1 e E6). 
No quesito vias de transmissão, estudos sugerem as vias: oral-oral e fecaloral. A condição socioeconômica, especialmente na infância, está fortemente relacionada à maior prevalência da infecção pela HP, pois condições precárias de saneamento básico, aglomerações familiares, o consumo de água não tratada e maus hábitos de higiene estão associadas a maiores taxas evidenciadas ${ }^{2,24}$.

Outro aspecto relevante é a possibilidade de contaminação devido ao hábito de consumir alimentos gordurosos ou ácidos, bem como horas prolongadas sem alimentação (E2, E12 e E13). Mas estudos mostram que estes fatores na realidade favorecem o desenvolvimento de lesões provenientes da bactéria já instalada na mucosa gástrica, portanto não é considerado um meio de transmissão da HP. Para reafirmar isso, aborda-se Hora ${ }^{5}$, relatando que os pacientes infectados pela HP que possuem o hábito de consumir alimentos irritantes da mucosa gástrica aumentam o risco de desenvolvimento de úlceras pépticas.

A saliva contaminada através do regurgitamento do suco gástrico parece atuar como um possível meio de transmissão desta bactéria Assim, cogita-se a hipótese de que pode ser transmitida entre marido e mulher ou de mãe para filho ao realizar pré-mastigação dos alimentos e a limpeza da chupeta com a boca antes de dar ao bebe ${ }^{2}$.

Mas o que chama mais atenção é o fato de que essa transmissão possa ocorrer a partir da utilização de aparelhos endoscópicos contaminados por secreções gástricas, atuando como possível forma de transmissão iatrogênica da $\mathrm{HP}$, principalmente quando a lavagem do aparelho é realizada de forma manual ${ }^{3}$.

Apesar dos enfermeiros terem mostrado conhecimento sobre os possíveis meios de transmissão da bactéria, nota-se que são vias fragmentadas e em nenhum momento nas falas relatam que por conta dessa forma ou de outra de contaminação poderia haver a necessidade de trabalhar a educação em saúde com a comunidade no sentido de evitar a contaminação e recontaminação.

De acordo com Nierdele e Moreira ${ }^{25}$, a maioria da população brasileira, incluindo os mais esclarecidos (com maior nível de escolaridade), desconhece a HP, fato que causa preocupação, pois estima-se que metade da população mundial pode estar contaminada pela bactéria. O diagnóstico precoce da HP e o tratamento adequado poderia levar a uma redução das complicações desta infecção, inclusive o câncer gástrico. 
Artigo Original

Atenção à Saúde

Alguns relatos corroboram com as afirmativas supracitadas, quando os enfermeiros mencionam a falta de conhecimento sobre a temática:

“Não sei a transmissão" (E7, E8).

"Nem imagino. [...] tive que fazer exame, mas nunca me interessei em saber mais sobre o assunto" (E9).

Salienta-se que é relevante pensar nos assuntos que os profissionais não apresentam esclarecimentos e a partir disso fomentar a educação permanente, pelo fato de que tais profissionais de saúde exercem um papel importante na prevenção de doenças na população.

Subcategoria 3: Riscos iminentes à Saúde

Quando questionado aos enfermeiros sobre as afecções que podem ser causadas pela HP depois de instalada, teve-se como respostas gerais a gastrite, a úlcera no trato gastrointestinal superior. Mas, o câncer também foi citado.

"Gastrite, úlcera e duodenite" (E1).

"[...] úlcera do duodeno. Não sei se podem ocorrer infecções intestinais" (E3).

[...] pode levar ao câncer. Acho que gastrite crônica" (E8).

"Gastrite, esofagite e ulcera" (E10).

Todas as afecções citadas são desgastantes às pessoas acometidas e a literatura reafirma sua existência. A literatura é ampla, aborda todas as inflamações do trato gastrointestinal e o câncer, portanto, resolveu-se abordar e enfatizar todas elas na análise dessa categoria. 
A HP de fato está envolvida na maioria dos casos de gastrite crônica e úlcera gástrica, podendo evoluir para câncer gástrico ${ }^{25}$. Muller et al. ${ }^{26}$ identificaram a prevalência de $77 \%$ de gastrite crônica não-atrófica em pacientes dispépticos infectados pela HP.

O conjunto da ação corrosiva no tecido gástrico ocasionada por ácido e pepsina nas úlceras pépticas, somada à presença da HP e ao uso frequente de antiinflamatórios não esteroidais (AINES) são considerados agentes agressores deste tecido, gerando desequilíbrio no sistema de proteção da mucosa gástrica ${ }^{27}$.

Além disso, o estudo realizado por Stippet et al.$^{28}$ mostrou maior prevalência da infecção pela HP na população de pacientes sem esofagite de refluxo, quando comparados com os pacientes com esofagite, todavia, ainda são necessários maiores estudos para avaliar a relação entre HP e doença de refluxo gastrointestinal (DRGE).

Um dos riscos levantados e que determina uma evolução desgastante e nem sempre de cura é o câncer gástrico, uma vez que vários estudos mostram a relação do seu desenvolvimento com a infecção persistente da HP na mucosa gástrica, e, segundo Meine ${ }^{29}$, estima-se que cerca de $1-2 \%$ da população poderá chegar a desenvolver câncer gástrico. Inclusive preocupa o fato de que a HP é considerada pela Organização Mundial de Saúde como um agente carcinogêneo do tipo ${ }^{9}$, sendo, no Brasil, o terceiro tipo de câncer responsável pela mortalidade de homens e o quinto entre as mulheres ${ }^{8}$.

Contudo, ao perceber o sério risco que uma bactéria pode gerar ao ser humano, é considerável pensar estratégias para a prevenção de infecção ou reinfecção da mesma. Porém, acredita-se que "apesar da alta prevalência de indivíduos com HP com as complicações consequentes da colonização desta, boa parte da população não tem conhecimento ou sequer ouviu falar sobre a bactéria" 25 . 
Subcategoria 4: Tratamento medicamentoso versus educação em saúde

Quando se fala sobre tratamento, lembra-se do enfoque medicamentoso, mas, na HP, esse requer muito mais do que isso, uma vez que a educação em saúde é um método adequado para a prevenção da contaminação ou reinfecção. $\mathrm{Na}$ atenção básica há possibilidades únicas de intervenções educativas que podem surtir resultados se forem efetivamente investidos tempo e conhecimento para essa causa.

De um modo geral, o tratamento à base de antibióticos e protetores gástricos foi citado como primeira linha de tratamento conhecido pelas enfermeiras.

Nas Diretrizes para diagnóstico e erradicação da HP utilizando medicamentos da Atenção Primária - SUS indica como primeira linha de tratamento da infecção por HP a associação de "um inibidor de bomba de prótons (em dose padrão) à claritromicina $0,5 \mathrm{~g}$ e à amoxicilina $1,0 \mathrm{~g}$ (Terapia Tripla) administrados duas vezes ao dia por 07 dias"30.

Percebeu-se que é de conhecimento das enfermeiras entrevistadas os medicamentos utilizados, com algumas exceções, mas nenhuma menciona outro tipo de acompanhamento ou tratamento, exceto o químico.

Caso o tratamento não seja completo e efetivo pode haver a resistência bacteriana e o aumento na disseminação, que podem ser diminuídas a partir de estratégias voltadas à educação em saúde ${ }^{31}$. O envolvimento do enfermeiro capacitado da atenção básica torna-se essencial nesta fase, pois é ele quem tem a principal função de orientador, prestando informações à população referente aos meios de contaminação, tentando deste modo reduzir o índice de recontaminação.

Categoria 2: Modelo Biomédico de Atenção

O modelo biomédico é caracterizado pela prática da assistência curativista e hospitalocêntrico, centrado apenas na consulta médica. Historicamente o Brasil é marcado pelo predomínio deste modelo de prática assistencial ${ }^{32}$.

A realidade curativista toma um novo rumo, se constrói com outro aspecto voltado ao modelo assistencial de promoção à saúde, que se constitui em um 
desafio na atenção primária em saúde, pois tem o objetivo de desconstruir as matrizes de um modelo assistencial hegemônico ainda predominante ${ }^{33}$.

Assim, com o advento da atenção básica, essa prática já não supria a necessidade exposta pela população, portanto, no final da década de 80 e início dos anos 90 foi necessário repensar o sistema de saúde brasileiro e, com isso, houve um movimento que proporcionou "a reestruturação do modelo assistencial à saúde iniciou-se após a implantação do Sistema Único de Saúde (SUS) e, sobretudo, a partir da criação do Programa Saúde da Família (PSF), em 1994"32.

No que tange a atenção primária, modelo de nosso sistema brasileiro, de acordo com Silva e Caldeira ${ }^{32}$, "enquanto a percepção de um novo modelo assistencial não for assumida pelas equipes da Estratégia de Saúde da Família (ESF), a prática centrada na consulta do médico e na abordagem da doença não será transformada".

O presente estudo corrobora com a afirmativa de Silva e Caldeira ${ }^{32}$, quando os enfermeiros entrevistados afirmam que o médico da UBS é o profissional responsável pelo tratamento e orientações quanto ao tratamento da HP, e o enfermeiro exerce pouca ou nenhuma influência na mudança de atitudes da clientela com relação à bactéria:

"[...] Nunca teve nenhum paciente para orientar. Geralmente é o médico quem orienta [...]" (E11).

"[...] O paciente com o diagnóstico de HP positivo é encaminhado para a consulta médica seguindo as orientações do profissional que realizou a Endoscopia [...]" (E12).

"[...] Quando o paciente vem com o diagnóstico de HP positivo, encaminho para a consulta médica [...]" (E15).

As falas dos enfermeiros evidenciam o predomínio do modelo de atenção centrado na consulta médica, com enfoque apenas no tratamento e cura da doença, ao invés de ter investimentos coletivos e individuais na prevenção inclusive de uma reinfecção. 
Nota-se que a produção de vínculo entre comunidade e ESF é influenciada pelo atendimento médico. Ficou evidente que as enfermeiras não consideram a possibilidade de participarem do cuidado ao paciente com HP, confiando esta responsabilidade ao médico.

Categoria 3: Relato de experiência da Intervenção Educativa

O encontro para a realização da intervenção educativa foi realizado em 03 de Outubro de 2014, no período da tarde, durante a reunião mensal das enfermeiras da atenção básica organizada pela coordenação da ESF do município onde atuam as participantes desse estudo. Participaram do encontro as 15 enfermeiras entrevistadas, a coordenadora geral da Estratégia de Saúde da Família (ESF) e duas enfermeiras do Projeto Saúde na Escola (PSE).

A partir do uso de recurso áudiovisual e uso de fotos/imagens ilustrativas iniciou-se a apresentação com o título do estudo: "A importância da intervenção educativa aos enfermeiros da atenção básica para a prevenção do Helicobacter Pylori”. A apresentação foi realizada de forma sucinta, abordando os principais assuntos sobre a temática da HP, como: conceito, fatores de risco, forma de transmissão, meios diagnósticos, tratamento e prevenção, este último com maior enfoque buscando conscientizar as enfermeiras da atenção básica sobre a importância da sua atuação na comunidade para a prevenção da HP. Salientou-se que não adianta somente um tratamento medicamentoso eficaz se não houver orientação ao paciente quanto às formas de prevenção de uma nova infecção pela bactéria; ou até para evitar novas complicações como hemorragias gastrointestinais.

A apresentação, no ver das enfermeiras participantes, contribuiu de forma positiva, pois relataram que o assunto é de grande importância para a saúde pública e, pelo fato de não disponibilizarem de tempo para adquirirem mais conhecimento, o assunto acaba caindo no esquecimento.

"É importante nos atualizarmos, pois considero um assunto de grande importância” (E5).

"Contribuiu porque com a rotina do dia a dia na unidade não 
O assunto abordado foi considerado de grande relevância para a enfermagem, pois dentro da UBS é visto frequentemente o diagnóstico positivo para HP. A educação continuada com a equipe e usuários é o método inicial para a educação e saúde na forma preventiva.

"Para podermos educar e orientar os pacientes" (E9).

"Sim. Pois temos na unidade pacientes com estes sintomas todos os dias" (E10).

"Sim. Para que possamos atuar também na forma preventiva da doença” (E12).

A partir das falas acima, percebe-se que a capacitação serviu para fortalecer o conhecimento e para possível utilização e mudança na prática. Afirmam que utilizarão métodos que abordem a educação em saúde na comunidade onde atuam e através de grupos educativos já existentes, nas consultas de enfermagem e também no acolhimento ao paciente.

"Sim. No momento do acolhimento dos pacientes e em grupos de educação e saúde" (E5).

"Sim. Durante as consultas de enfermagem" (E9).

"Sim. Dentro da própria casa e com familiares. É uma corrente de repasse de informações" (E10)

"Sim. Nas reuniões de equipe e grupos terapêuticos" (E15). 
Uma das solicitações evidenciadas nas respostas foi que a secretaria de saúde promova mais educação continuada com as equipes do ESF, pois o conteúdo foi de grande relevância. Salienta-se que a coordenação das ESF esteve presente e presenciou todo o processo.

"O conteúdo é de grande relevância para podermos trabalhar ainda mais na prevenção de doenças" (E4).

"Que a secretaria de saúde promova educação continuada sobre o tema para as equipes do ESF" (E7).

\section{CONCLUSÃO}

As enfermeiras consideraram que a identificação dos fatores de riscos e o direcionamento das orientações são de extrema importância para a prevenção do HP, portanto se faz importante promover discussões e aprendizado sobre esse conteúdo. Fato que demonstra a importância da intervenção educativa com enfermeiros da atenção básica, devido ao conhecimento insuficiente frente à contaminação e transmissão da HP.

O enfermeiro exerce papel fundamental dentro da atenção básica, é ele quem organiza, direciona, presta o acolhimento e define estratégias de prevenção. $A$ integralidade do cuidado começa com orientações dentro deste campo de trabalho Ressalta-se, portanto, a importância destes profissionais para a comunidade em geral.

A contaminação pela bactéria não ocorre simplesmente, mas é resultante da conjunção de numerosos fatores de riscos ligados à comunidade, assim a compreensão dos mecanismos oportuniza a elaboração de estratégias de prevenção.

Percebeu-se a necessidade da capacitação junto a estes profissionais da saúde, para que as tornem instrumentalizadas para avaliar os fatores de risco e nortear suas condutas ante a ocorrência da infecção, consolidando seu papel de orientadora e promovendo a saúde. Desta forma, a melhor maneira é muni-las de 
Artigo Original

\section{Atenção à Saúde}

conhecimentos da epidemiologia da bactéria, o que vem a contribuir para a preparação de estratégias de prevenção de infecções.

O despreparo dos enfermeiros diante da temática foi atribuído à falta de capacitação desde a vida acadêmica e à falta de tempo devido à grande demanda de atividades e responsabilidades do enfermeiro dentro da atenção básica.

Destacou-se que, apesar da maioria dos profissionais da enfermagem possuir especialização em saúde coletiva, ainda há o predomínio de um modelo de atenção voltado para a cura do doente e direcionado à consulta médica, permanecendo o enfermeiro em atividades burocráticas, administrativas e pouco assistenciais voltadas para a promoção da saúde e prevenção de doenças.

Os enfermeiros reconheceram a necessidade de aumentar o conhecimento sobre a temática a fim de prestar uma melhor assistência à comunidade e frente a isso sugeriram capacitação sobre o tema.

Assim, os pressupostos da pesquisa foram confirmados e os objetivos alcançados, uma vez que se acreditava na dificuldade de entendimento sobre o assunto, bem como a importância de se realizar uma prática educativa focada no entendimento para a promoção da saúde e prevenção do problema.

A intervenção educativa realizada foi de grande valia, pois a capacitação dos profissionais de enfermagem contribui para a melhoria da qualidade da assistência prestada ao paciente. Ao se capacitar, o profissional é transformado pelo que aprende, adquirindo condições amplas e plenas de atuar sobre o seu setor de trabalho.

Há de se pensar sobre a dificuldade em colocar em prática efetivamente as competências de cada profissional de saúde como o enfermeiro, uma vez que os modelos assistenciais vigentes ainda estão muitas vezes enraizados em práticas curativas e não preventivas ou de promoção da saúde. Assim, tal qual Lucena et al. ${ }^{34}$, propõe-se "um repensar acerca do saber/fazer da enfermagem, apontando possibilidades de expansão do seu campo de atuação, bem como dos limites e desafios a serem vencidos pelos profissionais da área".

Frente aos resultados obtidos propõem-se para o serviço de enfermagem a busca de conhecimento constante, pois somente o entendimento sobre os mecanismos de transmissão e epidemiologia da HP poderão influenciar na conduta do profissional na busca da prevenção e promoção à saúde com relação à bactéria. 
Artigo Original

Atenção à Saúde

Sugere-se que o enfermeiro trabalhe a temática nos grupos das UBS e em orientação individual, e não somente diante de um diagnóstico positivo, mas também visando à prevenção da infecção. Para que isto de fato ocorra é importante que a secretaria da saúde promova educação permanente em saúde para subsidiar o aperfeiçoamento da equipe de enfermeiros do município.

Para tanto, a efetivação de políticas públicas de educação permanente aparentemente parece ser um caminho a ser almejado e aplicado na prática cotidiana.

\section{REFERÊNCIAS}

1. Rezende JM. À sombra do plátano: crônicas de história da medicina. São Paulo: Editora Unifesp, 2009.

2. Kodaira MS, Escobar AMU, Grisi S. Aspectos epidemiológicos do Helicobacter pylori na infância e adolescência. Rev saúde pública. 2002:356-69.

3. Guimarães J, Corvelo TC, Barile KA. Helicobacter pylori: fatores relacionados à sua patogênese. Rev para med. 2008;22:33-8.

4. Moraes MMC, Silva GAP. Fatores de risco para infecção pelo Helicobacter pylori em crianças. J pediatr. 2003;79:21-8.

5. Hora JAB. Principais temas em gastroenterologia para residência médica. São Paulo: Medcel; 2008. 480 p.

6. Rodrigues RV, Corvelo TC, Ferrer MT. [Seroprevalence of Helicobacter pylori infection among children of different socioeconomic levels in Porto Velho, State of Rondonia]. Rev Soc Bras Med Trop. 2007;40(5):550-4.

7. Mincis $M$, Mincis $R$, Mincis $R$. Avanços no tratamento da bactéria Helicobacter pylori (HP). GED gastroenterol endosc dig. 2011;30(2):75-9.

8. Inca. Tipos de Câncer: Estômago: Instituto Nacional do Câncer; 2015 [cited 2014 set. 11]. Available from: http://www2.inca.gov.br/wps/wcm/connect/tiposdecancer/site/home/estomago/preven cao.

9. Sampaio A, Santos P. Factores genéticos do Helicobacter pylori e do hospedeiro na carcinogénese gástrica. Rev Port Cienc Biom. 2008:72-8. 
10. Organization WH. The World Health Report 2004: Changing History, Annex Table 3: Burden of disease in DALYs by cause, sex, and mortality stratum in WHO regions, estimates for 2002. Geneva: WHO. 2004;2004.

11. Rocha SMM, Almeida MCP. O processo de trabalho da enfermagem em saúde coletiva e a interdisciplinaridade. Revista Latino-Americana de Enfermagem Rev. 2000;8:96-101.

12. Feijão AR, Galvão MTG. Ações de educação em saúde na atenção primária: revelando métodos, técnicas e bases teóricas. Rev Rene. 2012;8(2).

13. Potter PA, Perry AG. Fundamentos de enfermagem. Rio de Janeiro: Elsevier Brasil; 2006.

14. Sousa LB, Torres CA, Pinheiro PNC, Pinheiro AKB. Práticas de educação em saúde no Brasil: a atuação da enfermagem. Rev enferm UERJ. 2010:55-60.

15. Martins C, Kobayashi RM, Ayoub AC, Leite MMJ. Perfil do enfermeiro e necessidades de desenvolvimento de competência profissional. Texto \& contextoenfermagem. 2006;15:472-8.

16. Paschoal AS, Mantovani MF, Méier MJ. Percepção da educação permanente, continuada e em serviço para enfermeiros de um hospital de ensino. Rev Esc Enferm USP. 2007;41:478-84.

17. Trivinos ANS. Introdução à Pesquisa em Ciências Sociais - A Pesquisa Qualitativa em Educação. SP: Atlas; 2008.

18. Sampieri RH. Metodologia de pesquisa. 5 ed. Porto Alegre: Penso; 2013.

19. Gil AC. Como elaborar projetos de pesquisa. Métodos e técnicas de pesquisa social. São Paulo: Atlas; 2002. p. 175.

20. Brasil. RESOLUÇÃO N 466 , DE 12 DE DEZEMBRO DE 2012: Conselho Nacional de Saúde; 2012. Available from: http://conselho.saude.gov.br/resolucoes/2012/Reso466.pdf.

21. Minayo MCS. Pesquisa social: teoria, método e criatividade. Petrópolis, RJ: Vozes; 2009.

22. Pastore E, Rosa LD. Trabalho e gênero da área da saúde. o Seminário. Passo Fundo/RS.2007. 
23. Machado MFAS, Monteiro EMLM, Queiroz DT, Vieira NFC, Barroso MGT. Integralidade, formação de saúde, educação em saúde e as propostas do SUS: uma revisão conceitual. Ciênc saúde coletiva. 2007;12:335-42.

24. Barbosa JA, Schinonni MI. Helicobacter pylori: Associação com o câncer gástrico e novas descobertas sobre os fatores de virulência. Rev ciênc méd biol. 2012;10(3):254-62.

25. Niederle R, Moreira AC. O PERIGO PODE ESTAR NO ESTÔMAGO: Helicobacter pylori-Aspectos Epidemiológicos, Patológicos, de Tratamento e Preventivos. Rev Contexto Saúde. 2013;10(19):59-66.

26. Muller LB, Fagundes RB, Moraes CC, Rampazzo A. Prevalência da infecção por Helicobacter pylori e das lesões precusoras do câncer gástrico em pacientes dispéticos. Arq gastroenterol 2007;44:93-8.

27. Carvalho MMCM. Úlcera péptica: Etiopatogenia, diagnóstico, aspetos clínicos e tratamento [Dissertação]. Porto: Universidade Fernando Pessoa; 2013.

28. Stipp WN, Souza AR, Sakae TM. Avaliação endoscópica da doença do refluxo gastroesofágico e relação com a infecção pelo helicobacter pylori. ACM arq catarin med. 2007;36(3):29-33.

29. Meine GC. Relação entre infecção pelo helicobacter pylori linhagem cagApositiva e risco de câncer gástrico [Dissertação]: Universidade Federal do Rio Grande do Sul.; 2006.

30. Júnior AAG. Diretrizes para diagnóstico e erradicação do $H$. Pylori utilizando medicamentos da Atenção Primária SUS.: CCATES/UFMG; 2014.

31. Oliveira CB, Frechiani JM, Silva FM, Maciel ELN. As ações de educação em saúde para crianças e adolescentes nas unidades básicas da região de Maruípe no município de Vitória. Ciênc Saúde Coletiva. 2009;14:635-44.

32. Silva JM, Caldeira AP. Modelo assistencial e indicadores de qualidade da assistência: percepção dos profissionais da atenção primária à saúde. Cad saúde pública 2010;26:1187-93.

33. Costa GD, Cotta RMM, Ferreira MLSM, Reis JR, Franceschini SCC. Saúde da família: desafios no processo de reorientação do modelo assistencial. Rev bras enferm 2009;62:113-8. 
Artigo Original

Atenção à Saúde

34. Lucena AF, Paskulin LMG, Souza MF, Gutiérrez MGR. Construção do conhecimento e do fazer enfermagem e os modelos assistenciais. Rev Esc Enferm USP. 2006;40:292-8. 